\title{
Scour at partially blocked box-culverts under steady flow
}

1 Sayana Sorourian BSc Eng, MSc Eng PhD Candidate, School of Civil and Environmental Engineering, University of Technology Sydney, New South Wales, Australia

2. Alireza Keshavarzi MSCivEng, PhD Visiting Professor, School of Civil and Environmental Engineering, University of Technology Sydney, New South Wales, Australia
3. James E. Ball MSCivEng, PhD

Associate Professor, School of Civil and Environmental Engineering, University of Technology Sydney, New South Wales, Australia
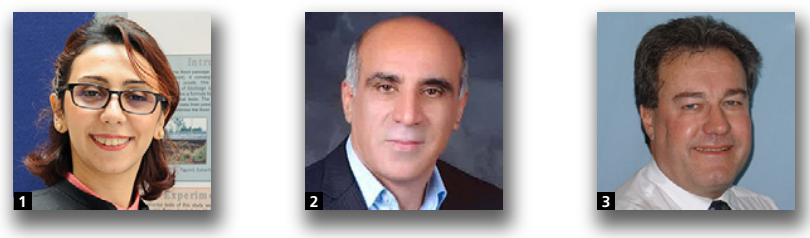

Culverts are built at locations where a waterway crosses a road or railway and creates a limitation to flow passage. Furthermore, blockage commonly occurs during flood events with accumulation of debris at the culvert inlet. The inlet blockage changes the flow structure at the outlet and may result in culvert failure. Despite this, the impacts of blockage on culvert hydraulics and downstream waterways have not received consideration in the literature. The purpose of this paper is to mitigate this deficiency by reporting on an investigation into scouring at the outlet of partially blocked culverts. Experimental tests were conducted under steady flow to investigate a relationship between the maximum scour depth, blockage ratio of the culvert and the flow characteristics. Both non-blocked and partially blocked conditions were considered. Consideration of the results obtained showed that the scoured area and maximum scour depth increased with partially blocked culverts conditions compared with equivalent non-blocked culverts.

\section{Notation}

$A$

$A_{\mathrm{S}}$

B

$d_{\mathrm{s}}$

$d_{\mathrm{sm}}$

$d_{0}$

$d_{50}$

$F_{\mathrm{d}}$

$F_{\text {r }}$

g

H

$h_{\mathrm{B}}$

$h_{\mathrm{d}}$

$h_{\mathrm{t}}$

$h_{\mathrm{u}}$

$\mathrm{KE}_{x}$

$L_{\mathrm{t}}$

Q

$R^{2}$

RSS

$S$

$S_{\mathrm{E}}$ cross-sectional area of culvert outlet

scoured area

blockage ratio

scoured depth

maximum scour depth

outlet diameter in circular-shaped culverts

median grain size of bed material

densimetric Froude number

flow Froude number

acceleration of gravity

culvert height

height of blockage plate

depth of water at culvert outlet

tail water depth

upstream depth of water

kinetic energy in $x$ direction

total length of scouring hole

flow rate

coefficient of correlation

Reynolds shear stress

culvert slope

standard error of estimate
$\mathrm{TI}_{x} \quad$ turbulence intensity in $x$ direction

$t \quad$ time of experiment

$U_{*} \quad$ shear velocity at culvert outlet

$V_{x} \quad$ flow velocity in $x$ direction

$v_{x}^{\prime} \quad$ turbulent fluctuations of flow velocity in $x$ direction

$W \quad$ culvert width

$W_{t} \quad$ maximum scour width

$X \quad$ horizontal axis (flow direction)

$x_{s} \quad$ horizontal distance from the outlet

$x_{\mathrm{sm}} \quad$ location of maximum scour depth along horizontal axis

width of scour hole at any location along $Y$-axis

$\begin{array}{ll}y_{\mathrm{s}} & \text { depth of water from culvert invert }\end{array}$

$\rho \quad$ water density

$\rho_{\mathrm{s}} \quad$ sediment density

$\sigma_{g} \quad$ sediment geometric standard deviation

\section{Introduction}

Culverts are locations in water courses where a flow constriction occurs and therefore where blockage of some type may occur. Consideration of the number of culverts highlights the importance of culvert structures and their functional requirements. Weeks et al. (2009) reported on the damage resulting 
from blockage of culverts and waterways. In terms of functionality, blockage of culverts and bridges during floods is an important issue for many road authorities and local councils. Furthermore, blockage at culverts creates a risk of damage to private properties and public assets (Weeks et al., 2009). An analysis of the literature indicates that the two different research fields important in understanding this topic are

- culvert blockage

$\square$ scouring downstream of the culvert, that is, scour at the culvert outlet.

The first category generally consists of research based on field data collected after major floods. In these studies the main focus has been on the factors leading to blockage and the consequences of blockage on the downstream flow paths. For instance, Rigby et al. (2002) collected field data after a flood event and reported that, when the opening size of culverts is less than $6 \mathrm{~m}$ (measured diagonally) there is a high risk of culvert blockage, while Barthelmess and Rigby (2011) estimated culvert and bridge blockage based on availability, mobility and transportability of debris. Rigby and Barthelmess (2011) also explored culvert blockage mechanisms and their impact on flood behaviour. They reported that one of the consequences of blockage was flow diversions during flood events. They reported that even small blockages created diversions that would not usually occur and considerably changed flood behaviour.

The second group of research studies comprises those considering the scouring phenomena at the outlet of culverts. Several equations have been developed to estimate the maximum scouring depth at culvert outlets when the culvert is not blocked. Results from some of the more recent studies are presented herein for the purpose of comparison with the experimental data collected as part of the present study. In particular the data of the studies Lim (1995), Ade and Rajaratnam (1998), Sarathi et al. (2008) and Emami and Schleiss (2010) were used for this purpose.

There are many factors that influence scour downstream of a culvert outlet, including flow velocity, flow discharge, sediment size, tail water depth, culvert shape and culvert slope. While there have been numerous studies considering this problem, no reported study has considered all the influencing factors.

Bohan (1970) investigated scour dimensions at the culvert outlet using scale models. Bohan developed an equation based on the flow Froude number and experimental duration. Additionally, Bohan reported that culvert shape did not have a significant effect on scour hole geometry. However, Abt et al. (1987) concluded the opposite when they investigated the influence of culvert shape on scouring depth at the culvert outlet, and determined that scour dimensions developed at the outlet of circular-shaped culverts are significantly different from those arising from culverts with other shapes. Abt et al. also developed an equation to correlate the maximum scour depth to a modified discharge intensity where the discharge intensity is a modified form of the Froude number and is defined by

$$
\text { 1. } D I=\frac{Q}{A\left(g R_{\mathrm{H}}\right)^{0.5}}
$$

where $Q$ is discharge, $A$ is cross-sectional area; $\boldsymbol{g}$ is acceleration due to gravity and $R_{\mathrm{H}}$ is the culvert hydraulic radius.

Abt et al. (1986) studied the effect of culvert slope on the scour depth at the outlet of a culvert and noted that a steep culvert can increase the maximum scour depth by $10-40 \%$ over the scour dimensions for a horizontal culvert. Abida and Townsend (1991) developed an equation for local scour downstream of box-culverts relating flow Froude number and sediment size. Abt et al. (1996) estimated the dimension of outlet scour in relation to culvert discharge, hydraulic radius, time and material gradation. The effect of culvert slope and outlet drop was considered also. Although this formula was quite comprehensive, it lacked simplicity.

Some researchers - see Rajaratnam and Berry (1977), Ali and Lim (1986), Lim (1995), Day et al. (2001), Liriano et al. (2002), Sarathi et al. (2008) and Emami and Schleiss (2010) used the densimetric Froude number to estimate the scouring depth at the outlet of culverts and wall jets. The densimetric Froude number, which incorporates many of the influencing factors, is defined as

$$
\text { 2. } \quad F_{\mathrm{d}}=\frac{u}{\sqrt{\left[\left(\rho_{\mathrm{s}} / \rho\right)-1\right] \boldsymbol{g} d_{50}}}
$$

where $u$ is mean flow velocity, $\rho_{s}$ is sediment density, $\rho$ is water density, $\boldsymbol{g}$ is acceleration due to gravity and $d_{50}$ is median grain size of the sediment.

From consideration of Equation 2, it can be seen that velocity of flow, sediment size and sediment density are the primary influencing parameters. Factors that influence the flow velocity include the culvert slope, shape, flow rate and the tail water level.

Rajaratnam and Berry (1977) studied erosion at the outlet of circular wall jets both in non-cohesive sand and polystyrene. They concluded that the main characteristics of the scour hole, such as maximum scour depth and the location of deepest scour depth from the outlet, are functions of the densimetric Froude number. Ali and Lim (1986) investigated the effects of changing tail water depth on scouring downstream of the culvert outlet. They pointed out that tail water depths significantly affected the scour depth at the culvert outlet. They also noted that there is a critical tail water depth beyond which any changes in tail water will result in increase of scour depth. 
Lim (1995) conducted experimental tests on a circular unsubmerged culvert and compared his work with that of Abt et al. (1984) and Breusers and Raudkivi (1991). Lim highlighted the limitations of the formulations proposed by Abt et al. (1984) and Breusers and Raudkivi (1991) compared with his work and proposed equations to encompass the data based on the sediment densimetric Froude number. Day et al. (2001) investigated the effects of tail water depth and model scale on the maximum depth of scouring using the data collected from experimental testing of circular culverts. Liriano et al. (2002) studied scour at the outlet of culverts influenced by turbulent flow and pointed out that the peak values of turbulence intensities over the fixed bed coincided with the location of the maximum scour depth for a fully developed scour hole. Sarathi et al. (2008) studied the effect of nozzle size to sediment diameter at the downstream of square wall jets and noted that, for a certain value of densimetric Froude number, the evolution of scour depends on the ratio of nozzle size to grain size. However, they concluded that, for the equilibrium condition, the scour hole is independent of nozzle size to grain size. Emami and Schleiss (2010) conducted some experimental tests to evaluate the natural mobile bed erosion without any protection. They compared their work with some previous studies and proposed an equation for maximum scour depth based on their experimental tests.

From consideration of these previous studies, it can be concluded that the main factors influencing the maximum scour depth downstream of a culvert are sediment properties such as median grain size and geometrical standard deviation, flow conditions and depth of tail water. Some research has indicated that the geometry of the culvert and its slope also affects the formation of the scour hole. Most formulas proposed in this regard are functions of densimetric Froude number, median grain size of bed material, depth of water downstream from the culvert and size of culvert opening. In previous studies, blockage was not considered as a factor influencing the development of a scour hole; hence the focus has been on the scouring pattern at the outlet of the culvert in a non-blocked condition. However, culverts may be partially blocked and there is a need for a systematic study on partially blocked culverts. Hence, the focus of this study was to investigate the flow characteristics and scouring pattern of a partially blocked culvert.

\section{Experimental set-up}

An experimental programme was designed to investigate the relationship between the maximum scour depth, blockage ratio of the culvert and flow characteristics. The experimental tests were conducted for two different conditions

non-blocked

- partially blocked.

The experimental set-up was located in the UTS hydraulics laboratory and consisted of a rectangular flume fed by a static tank. The plan view and longitudinal profile of this flume are shown in Figure 1. The concrete flume is $19 \mathrm{~m}$ long with a width and depth of 605 and $600 \mathrm{~mm}$, respectively. The test section was located $9 \mathrm{~m}$ from the inlet of the flume to ensure a fully developed flow would reach the test section. The test section was a $4 \mathrm{~m}$ long, $150 \mathrm{~mm}$ deep sand basin with the same width as the flume. Water flow in the flume is controlled through a valve, while, at the downstream end of the flume, a sluice gate was installed to adjust the downstream water depth.

The box-culvert model being tested was placed in the flume on a sand bed. The culvert model details are shown in Figure 2.

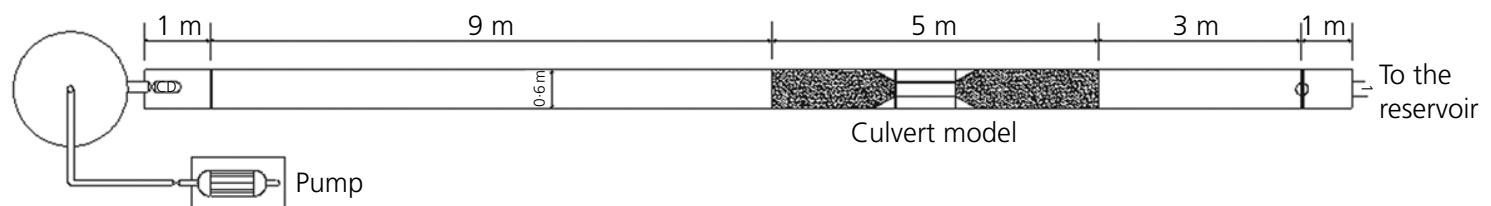

(a)

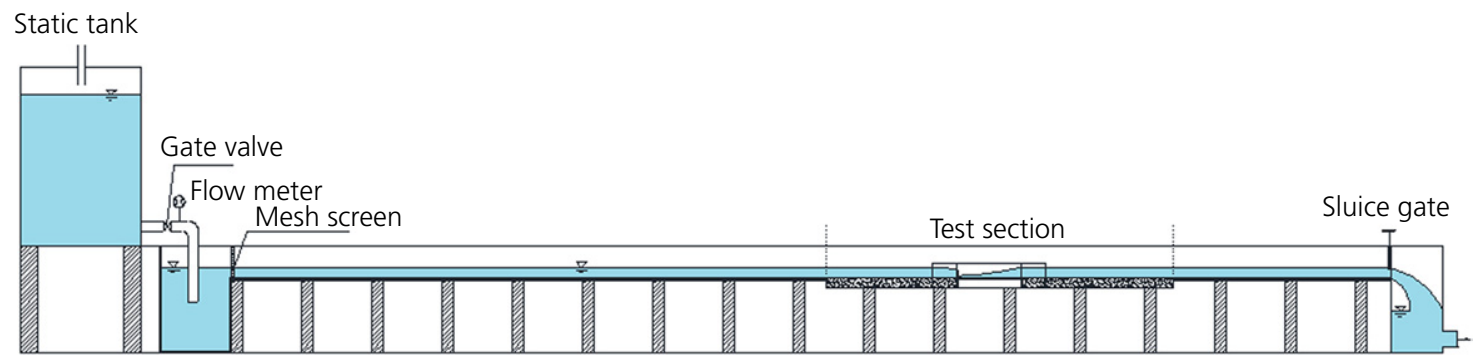

(b)

Figure 1. Experimental test facility in hydraulics laboratory:

(a) plan view; (b) section view 


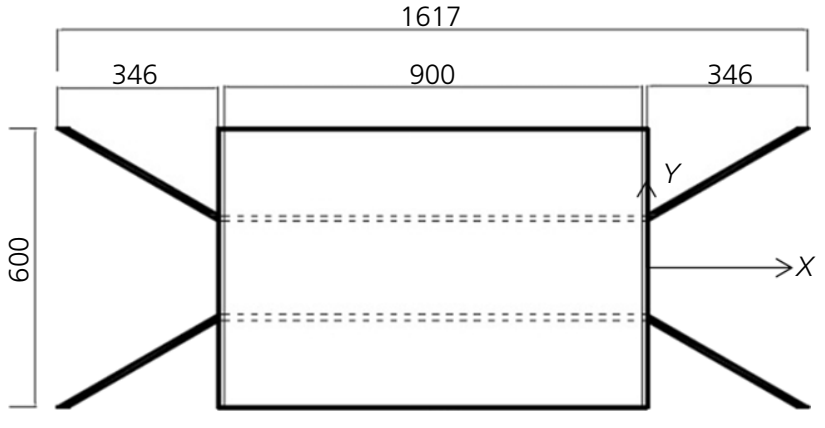

(a)

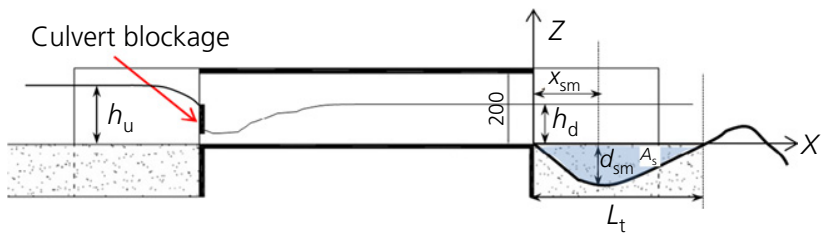

(b)

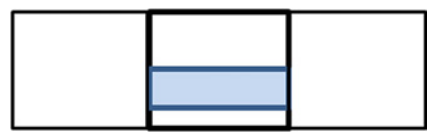

(c)

Figure 2. Culvert model and coordinate system: (a) plan view; (b) section view; (c) inlet view (units: $\mathrm{mm}$ )

The opening of the culvert is $200 \times 200 \mathrm{~mm}$ and the length of the culvert barrel is $900 \mathrm{~mm}$. There are transitions with $30^{\circ}$ flare at the inlet and outlet of the culvert. To simulate blockage at the inlet, a plate was installed at the opening of the culvert. Two sizes of plates $(200 \times 80$ and $200 \times 120 \mathrm{~mm})$ were used to obtain variable blockage ratios in the experimental tests. The sediment materials used in this study were uniform non-cohesive sand with median grain sizes $\left(d_{50}\right)$ of 0.85 and $2.0 \mathrm{~mm}$.

To measure bed profile and velocities in the $x, y$, and $z$ dimensions, a Nortek Vectrino Profiler, was used. This device is an Acoustic Doppler Velocimeter which is generally known as ADV. This instrument has four receive transducers set $90^{\circ}$ apart, mounted inside a receiver arm. The transmit transducer is in the centre of the probe. The ADV Profiler can take a velocity profile of a layer. The measuring volume is in a distance of 40 to $70 \mathrm{~mm}$ below the probe to get a full profile and 45 t0 $55 \mathrm{~mm}$ below the probe for point measurement. Operating temperature for this ADV Profiler is $-4^{\circ} \mathrm{C}$ to $+40^{\circ} \mathrm{C}$. The ADV Profiler measures velocities from $0 \cdot 1$ to $+3 \mathrm{~m} / \mathrm{s}$ and is accurate to $\pm 0.5 \%$ within this velocity range. It collected up to 6000 samples per point with a sampling rate of $100 \mathrm{~Hz}$. These samples were then processed to determine average velocities. The ADV Profiler installed on a cart allowed for the movement of the instrument in all directions. The coordinate system was set with the origin at the culvert outlet (Figure 2). The positive $X$ dimension was measured downstream of the culvert, the $Y$ dimension laterally across the flume and the $Z$ dimension upward. As shown in Figure $2 h_{\mathrm{d}}$ refers to the water depth at the outlet of the culvert and the average velocity through the culvert is $u$. The maximum scour depth along the centreline is $d_{\mathrm{sm}}$ and the axial scour length downstream of the culvert is $L_{\mathrm{t}}$. In this text the culvert height is denoted by $H$.

Prior to each test the sand was levelled with the culvert inlet and outlet in the sand basin. Experimental tests were conducted in a steady-state condition. The range of flow rate varied from 5 to $25 \mathrm{l} / \mathrm{s}$, while the test durations were sufficient to ensure that an equilibrium condition for the scouring process was achieved.

Tests were conducted under free surface flow conditions. Each individual run is referred to, by the sand type (S), blockage condition (B) and experiment number for each set. For example, $\mathrm{S} 1$ represents sand type $1\left(d_{50}=0.85 \mathrm{~mm}\right)$ and $\mathrm{S} 2$ represent sand type $2\left(d_{50}=2 \mathrm{~mm}\right)$. B0 is used for tests in nonblocked condition and B40 and B60 are for partially blocked conditions. Tests where the nomenclature starts with $\mathrm{V}$ had velocity measurement in the culvert barrel as well.

Table 1 shows the test classifications. In this table $\sigma_{g}$ is the sediment geometric standard deviation, $h_{\mathrm{d}}$ is the depth of water at the outlet of the culvert, $h_{\mathrm{u}}$ is the upstream water level, $h_{\mathrm{t}}$ represents the tail water depth and $F_{\mathrm{d}}$ is the densimetric Froude number. The blockage of a culvert is represented by $B$, which is defined as $\left(h_{\mathrm{B}} / h_{\mathrm{u}}\right)$, where $h_{\mathrm{B}}$ is the height of the plate used as the blockage in the inlet of the culvert (see Figure 2(b)).

\section{Dimensional analysis}

As discussed earlier, scouring at the culvert outlet is related to

- flow discharge, $Q$

culvert width, $W$

- culvert height, $H$

- height of blockage, $h_{\mathrm{B}}$

upstream water level, $h_{\mathrm{u}}$

- downstream water level at the culvert outlet, $h_{\mathrm{d}}$

tail water depth, $h_{\mathrm{t}}$

median grain size of sediments, $d_{50}$

water density, $\rho$

- sediment density, $\rho_{\mathrm{s}}$

- culvert slope, $S$

acceleration due to gravity, $\boldsymbol{g}$

Using these parameters, scouring at the outlet of a culvert can be expressed as

3. $f\left(d_{\mathrm{s}}, Q, W, H, h_{\mathrm{B}}, h_{\mathrm{u}}, h_{\mathrm{d}}, h_{\mathrm{t}}, d_{50}, \rho, \rho_{\mathrm{s}}, S, \boldsymbol{g}\right)=0$ 


\begin{tabular}{|c|c|c|c|c|c|c|c|c|}
\hline Test & $d_{50}: m m$ & $\sigma_{\mathrm{g}}$ & $h_{\mathrm{d}}: \mathrm{mm}$ & $h_{\mathrm{t}}: \mathrm{mm}$ & $h_{\mathrm{u}}: \mathrm{mm}$ & $Q: 1 / s$ & $B$ & $F_{\mathrm{d}}$ \\
\hline S2B01 & 2 & $1 \cdot 23$ & 125 & 125 & 125 & $10 \cdot 1$ & 0.0 & $2 \cdot 2$ \\
\hline $\mathrm{S} 2 \mathrm{BO} 2$ & 2 & $1 \cdot 23$ & 155 & 155 & 155 & $12 \cdot 3$ & 0.0 & $2 \cdot 2$ \\
\hline $\mathrm{S} 2 \mathrm{~B} 03$ & 2 & $1 \cdot 23$ & 100 & 105 & 105 & $12 \cdot 8$ & 0.0 & $3 \cdot 6$ \\
\hline S2B04 & 2 & $1 \cdot 23$ & 120 & 120 & 120 & 8.6 & 0.0 & $2 \cdot 0$ \\
\hline $\mathrm{S} 2 \mathrm{~B} 05$ & 2 & $1 \cdot 23$ & 100 & 105 & 100 & $6 \cdot 6$ & 0.0 & $1 \cdot 8$ \\
\hline S1B01 & 0.85 & $1 \cdot 37$ & 200 & 197 & 198 & $14 \cdot 6$ & 0.0 & $3 \cdot 1$ \\
\hline $\mathrm{S} 1 \mathrm{~B} 02$ & $0 \cdot 85$ & $1 \cdot 37$ & 157 & 157 & 160 & $15 \cdot 0$ & 0.0 & $4 \cdot 1$ \\
\hline S1B03 & 0.85 & $1 \cdot 37$ & 170 & 170 & 174 & $18 \cdot 7$ & 0.0 & $4 \cdot 7$ \\
\hline S1B04 & $0 \cdot 85$ & $1 \cdot 37$ & 138 & 145 & 150 & $13 \cdot 2$ & 0.0 & $4 \cdot 1$ \\
\hline S1B05 & 0.85 & $1 \cdot 37$ & 95 & 108 & 95 & $14 \cdot 2$ & 0.0 & $6 \cdot 4$ \\
\hline S1B06 & 0.85 & $1 \cdot 37$ & 90 & 95 & 90 & $4 \cdot 9$ & 0.0 & $2 \cdot 3$ \\
\hline S1B07 & 0.85 & $1 \cdot 37$ & 55 & 50 & 75 & $7 \cdot 0$ & 0.0 & $5 \cdot 5$ \\
\hline VS1B08 & 0.85 & $1 \cdot 37$ & 90 & 100 & 130 & $15 \cdot 1$ & 0.0 & $7 \cdot 2$ \\
\hline VS2B01 & 2 & $1 \cdot 23$ & 140 & 143 & 140 & $10 \cdot 0$ & 0.0 & $2 \cdot 0$ \\
\hline S2B401 & 2 & $1 \cdot 23$ & 140 & 145 & 170 & $10 \cdot 7$ & 0.5 & $2 \cdot 1$ \\
\hline S2B402 & 2 & $1 \cdot 23$ & 155 & 160 & 185 & $12 \cdot 3$ & 0.4 & $2 \cdot 2$ \\
\hline S2B403 & 2 & $1 \cdot 23$ & 105 & 105 & 175 & $12 \cdot 8$ & 0.5 & $3 \cdot 4$ \\
\hline S2B404 & 2 & $1 \cdot 23$ & 110 & 115 & 145 & $8 \cdot 8$ & 0.6 & $2 \cdot 2$ \\
\hline S2B405 & 2 & $1 \cdot 23$ & 105 & 110 & 125 & $6 \cdot 6$ & 0.6 & $1 \cdot 7$ \\
\hline S1B401 & 0.85 & $1 \cdot 37$ & 195 & 195 & 210 & $14 \cdot 7$ & 0.4 & $3 \cdot 2$ \\
\hline S1B402 & 0.85 & $1 \cdot 37$ & 165 & 168 & 196 & $14 \cdot 6$ & 0.4 & $3 \cdot 8$ \\
\hline S1B403 & 0.85 & $1 \cdot 37$ & 60 & 60 & 195 & $15 \cdot 1$ & 0.4 & $10 \cdot 7$ \\
\hline S1B405 & 0.85 & $1 \cdot 37$ & 210 & 213 & 230 & $19 \cdot 8$ & $0 \cdot 3$ & $4 \cdot 0$ \\
\hline S1B406 & $0 \cdot 85$ & $1 \cdot 37$ & 150 & 145 & 200 & $20 \cdot 7$ & 0.4 & $5 \cdot 9$ \\
\hline S1B407 & 0.85 & $1 \cdot 37$ & 80 & 70 & 230 & $25 \cdot 0$ & $0 \cdot 3$ & $13 \cdot 3$ \\
\hline S1B408 & $0 \cdot 85$ & $1 \cdot 37$ & 70 & 70 & 120 & $4 \cdot 9$ & 0.7 & $3 \cdot 0$ \\
\hline S1B409 & $0 \cdot 85$ & $1 \cdot 37$ & 80 & 95 & 160 & $10 \cdot 1$ & 0.5 & $5 \cdot 4$ \\
\hline VS2B401 & 2 & $1 \cdot 23$ & 135 & 140 & 215 & $10 \cdot 5$ & 0.8 & $2 \cdot 2$ \\
\hline VS2B402 & 2 & $1 \cdot 23$ & 140 & 145 & 185 & $14 \cdot 3$ & 0.6 & $2 \cdot 8$ \\
\hline VS2B403 & 2 & $1 \cdot 23$ & 150 & 160 & 180 & $14 \cdot 1$ & 0.4 & $2 \cdot 6$ \\
\hline VS2B404 & 2 & $1 \cdot 23$ & 165 & 175 & 185 & $14 \cdot 1$ & 0.4 & $2 \cdot 4$ \\
\hline VS2B405 & 2 & $1 \cdot 23$ & 165 & 170 & 185 & $10 \cdot 7$ & 0.5 & $1 \cdot 8$ \\
\hline S2B601 & 2 & $1 \cdot 23$ & 130 & 130 & 190 & $10 \cdot 3$ & 0.6 & $2 \cdot 2$ \\
\hline S2B602 & 2 & $1 \cdot 23$ & 170 & 170 & 210 & $12 \cdot 5$ & 0.6 & $2 \cdot 0$ \\
\hline S2B603 & 2 & $1 \cdot 23$ & 130 & 130 & 195 & $12 \cdot 8$ & 0.6 & $2 \cdot 7$ \\
\hline S2B604 & 2 & $1 \cdot 23$ & 110 & 115 & 160 & $8 \cdot 8$ & 0.8 & $2 \cdot 2$ \\
\hline S2B605 & 2 & $1 \cdot 23$ & 90 & 105 & 135 & $6 \cdot 6$ & 0.9 & $2 \cdot 0$ \\
\hline S1B601 & 0.85 & $1 \cdot 37$ & 60 & 70 & 150 & $7 \cdot 0$ & 0.8 & $5 \cdot 0$ \\
\hline
\end{tabular}

Table 1. Experimental test classification

In this study the effect of $W$ and $H$ can be excluded, as the dimensions of the culvert were constant. Also, the culvert slope $S$, the water density $\rho$ and the sediment density $\rho_{\mathrm{s}}$ were constant and, therefore, could be disregarded in this dimensional analysis. Hence, suitable non-dimensional terms in the relationship become

4. $\frac{d_{\mathrm{s}}}{h_{\mathrm{d}}}=f\left(\frac{Q}{W h_{\mathrm{d}} \sqrt{\boldsymbol{g} d_{50}}}, \frac{h_{\mathrm{B}}}{h_{\mathrm{u}}}\right)$
The first non-dimensional parameter $\left(Q / W h_{\mathrm{d}} \sqrt{\boldsymbol{g} d_{50}}\right)$ is known as the densimetric Froude number $\left(F_{\mathrm{d}}\right)$, while the second parameter $\left(h_{\mathrm{B}} / h_{\mathrm{u}}\right)$ is defined as the blockage factor $(B)$ for this research.

The densimetric Froude number has been used to accurately predict the sediment discharge by Aguirre-Pe et al. (2003). Ade and Rajaratnam (1998) collected data from 13 different sources and concluded that the densimetric Froude number $\left(F_{\mathrm{d}}\right)$ was the main parameter influencing the local scouring. While Ade and Rajaratnam considered the densimetric Froude 
number, the effects of culvert blockage were not considered in their study.

The major non-dimensional parameters considered herein are the densimetric Froude number and the blockage factor; it is the inclusion of the blockage factor that is unique to this study.

\section{Results and discussion}

\subsection{Flow structure}

The longitudinal, lateral and vertical velocity components through the culvert centreline were measured for all tests. Figure 3 shows the distribution of streamwise velocity in a $50 \mathrm{~mm}$ layer of flow from the bed in non-blocked (VS1B05) and blocked conditions (VS1B405). Both tests were run under similar flow conditions.

The maximum velocity in the non-blocked condition was $0.28 \mathrm{~m} / \mathrm{s}$, but in the partially blocked condition the maximum velocity increased to a maximum of $0.75 \mathrm{~m} / \mathrm{s}$, which is 2.7 times greater than the non-blocked condition. Furthermore, as shown in Figure 3, the change in velocity near the culvert invert differs significantly between the partially blocked and non-blocked conditions.

The velocity components in all directions were measured for four tests and the turbulence intensity, turbulent kinetic energy

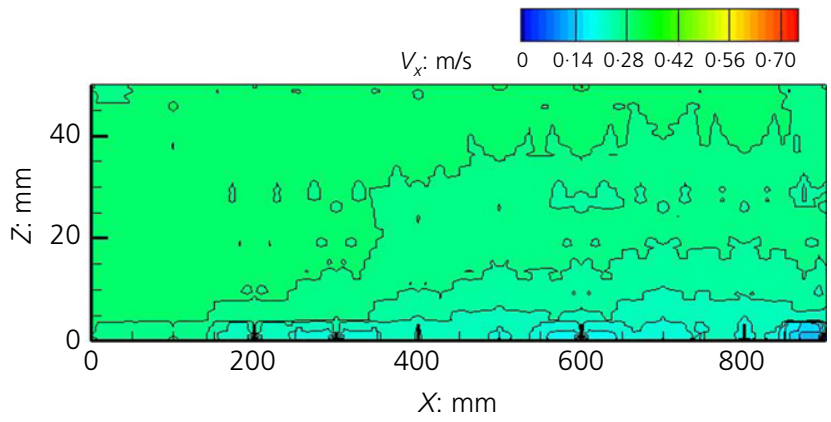

(a)

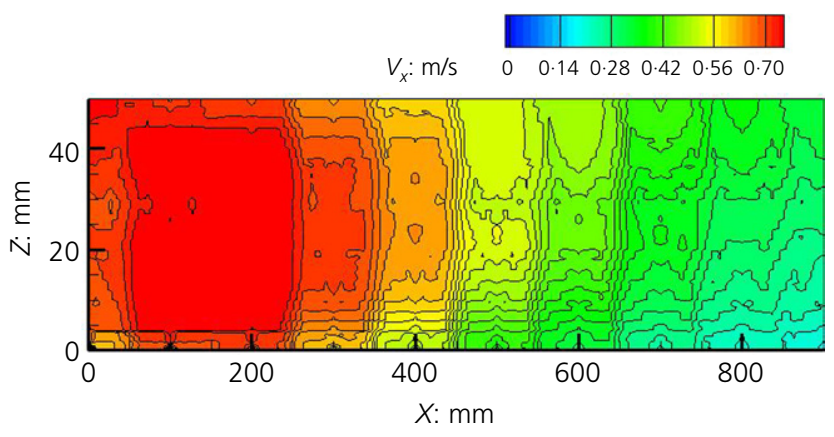

(b)

Figure 3. Velocity distribution in horizontal direction along the culvert barrel: (a) non-blocked; (b) partially blocked and Reynolds shear stress were calculated. Two of these tests were for a partially blocked culvert (VS1B403, VS1B405) and two were for a non-blocked condition (VS1B04, VS1B05). Figure 4(a) shows the depth-averaged velocity along the horizontal axis in the culvert barrel, normalised with shear velocity at the outlet of the culvert $\left(U_{*}\right)$. In the non-blocked condition the depth-averaged velocity remains constant along the culvert, while for the partially blocked condition the depth-averaged velocity decays from a maximum of 16 at the inlet to about 7 at the outlet.

Normalised turbulence intensity along the horizontal axis in the culvert barrel is shown in Figure 4(b). The turbulence intensity increases from 1.5 at the inlet to about 3.5 in the mid barrel and from there decreased to $2 \cdot 5$ at the outlet. In the nonblocked condition the turbulence intensity was around $0 \cdot 8$.

Figure 4(c) depicts the normalised turbulent kinetic energy along the horizontal axis in the culvert. As can be seen from this figure, the variation in turbulent kinetic energy along the culvert barrel was the same as the turbulence intensity at the culvert outlet. In partially blocked culvert, the normalised turbulent kinetic energy is about 2 at the culvert inlet, it increases to about 5 in mid-barrel and decays to 3 at the outlet. The maximum kinetic energy occurs at the middle of culvert barrel. While in non-blocked culvert, this parameter is about $0.7-1$ at the inlet and decreases to $0 \cdot 5-7$ at the outlet. The normalised kinetic energy ay the outlet of partially blocked culvert is about 6 times greater compare to non-blocked condition. This value is about six times greater than the normalised turbulent kinetic energy at the outlet for non-blocked flow conditions. Normalised Reynolds shear stress along the culvert barrel is shown in Figure 4(d). The normalised Reynolds shear stress (termed RSS) is defined as

5. $\quad \frac{\mathrm{RSS}_{x z}}{U_{*}^{2}}=\frac{\overline{v_{x}^{\prime} v_{z}^{\prime}}}{U_{*}^{2}}$

In Equation $5, v_{x}^{\prime}$ is the longitudinal turbulent velocity component and $v_{z}^{\prime}$ is the vertical turbulent velocity component. For non-blocked conditions, the depth-averaged values for normalised Reynolds shear stress remain constant and generally around $-0 \cdot 08$. For the partially blocked condition, the normalised Reynolds shear stress increases from zero at the inlet to about 1 at a location 0.4 along culvert. From the middle of the culvert the normalised shear stress becomes negative with a value of about -1.1 at a location of 0.7 along the barrel and to a value of -1 at the outlet of the culvert.

Although the depth-averaged velocity of the partially blocked condition at the outlet of the culvert decreased to reach the velocity of the non-blocked condition (Figure 4(a)), other flow characteristics such as turbulence intensity, turbulent kinetic 


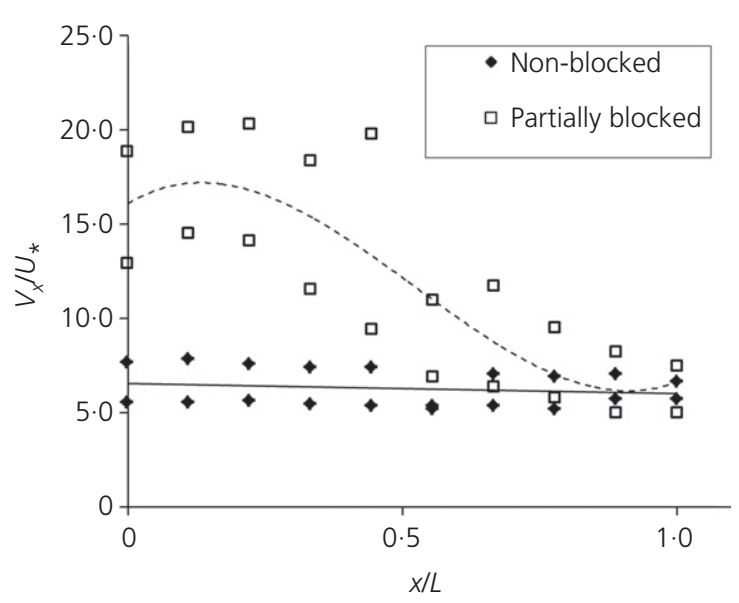

(a)

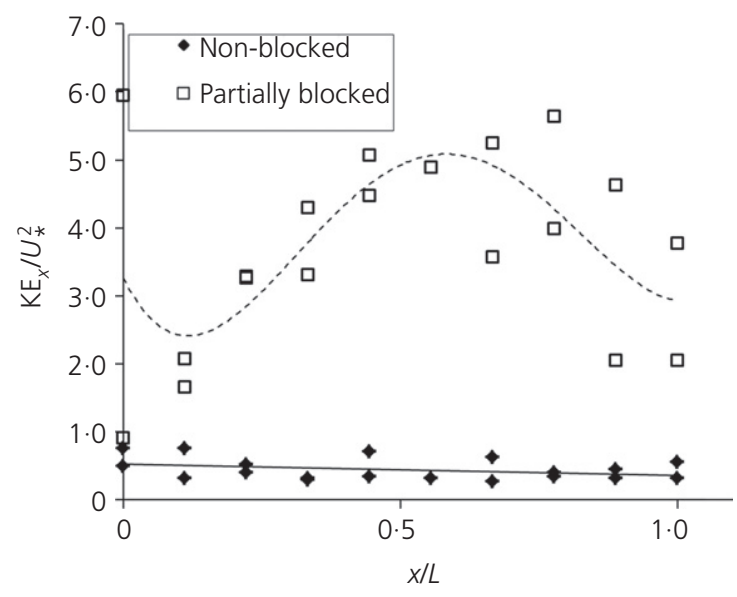

(c)

Figure 4. Non-dimensional flow characteristics of blocked and non-blocked conditions in culvert barrel: (a) velocity along horizontal axis depth averaged $\left(V_{x}\right)$; (b) turbulence intensity depth

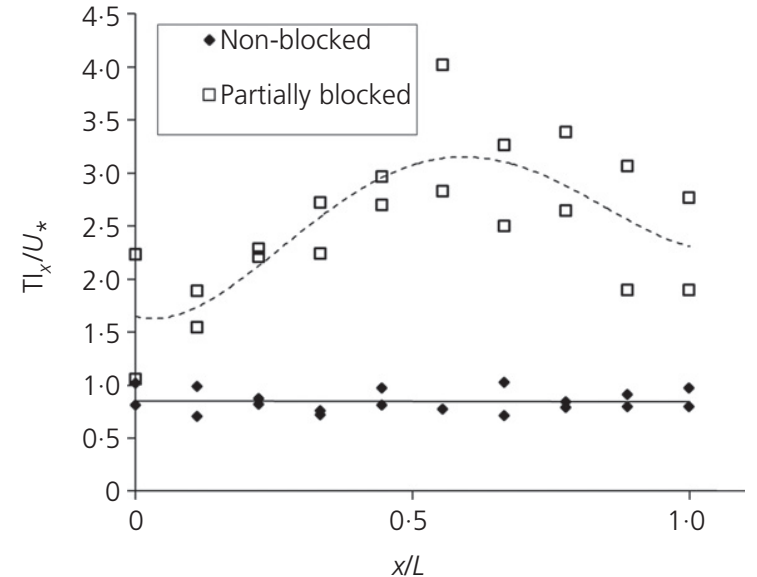

(b)

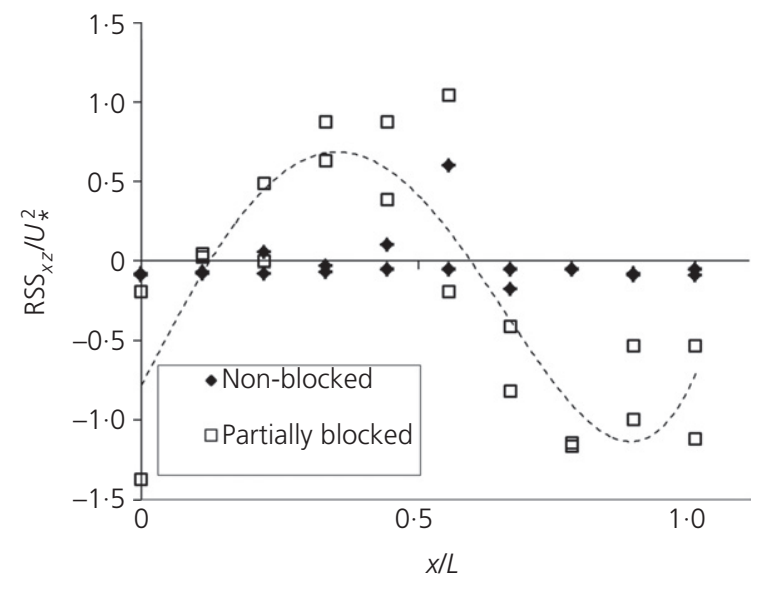

(d)

averaged $\left(T I_{x}\right)_{i}(\mathrm{c})$ kinetic energy depth averaged $\left(\mathrm{KE}_{\mathrm{x}}\right)$; (d) Reynolds shear stress depth averaged $\left(\mathrm{RSS}_{x z}\right)$ energy and Reynolds shear stress were much greater in the partially blocked condition.

Figure 5 shows the variation in the turbulence parameters with normalised depth at the culvert outlet for two sets of experimental tests. Set 1 includes test VS1B04 (non-blocked) and VS1B403 (blocked) and the set 2 includes VS1B05 (nonblocked) and VS1B405 (blocked). Each set of tests was conducted in the same flow condition (Table 1).

Figure 5(a) shows the normalised turbulence intensity $\left(\mathrm{TI}_{x} / U_{*}\right)$ in the $X$ direction at the outlet of the culvert $(x=900 \mathrm{~mm})$ plotted against normalised depth $\left(z / h_{\mathrm{d}}\right) . z$ is the depth of water from the bed, $h_{\mathrm{d}}$ is the total water depth at the outlet of the culvert and $U_{*}$ is the shear velocity at the outlet. The normalised turbulence intensity at the outlet of the culvert for the blocked condition is more than for the non-blocked condition in both sets of tests. The normalised turbulence intensity of the blocked condition equals 1.90 and 2.7 for set 1 and set 2, respectively. This parameter decreases to $0 \cdot 76$ and $1 \cdot 15$ in the non-blocked condition (Figure 5(a)).

The normalised turbulent kinetic energy $\left(\mathrm{KE}_{x} / U_{*}^{2}\right)$ of the flow in the non-blocked condition of set 1 is around $0 \cdot 3$ and not much change was observed. Likewise, the non-blocked condition of set 2 was around $0 \cdot 7$. Comparing the normalised kinetic energy in the blocked with the non-blocked condition, there is a 6.7 and 5.3 times increase for set 1 and set 2, respectively (Figure 5(b)).

Figure 5(c) shows the normalised Reynolds shear stress plotted against normalised water depth at the outlet of the culvert. Normalised Reynolds shear stress for the non-blocked condition of both sets is around $-0 \cdot 1$, while it reaches to -0.9 in the blocked condition for set 1 , and to $-1 \cdot 22$ in the blocked condition for set 2 (Figure 5(c)). 


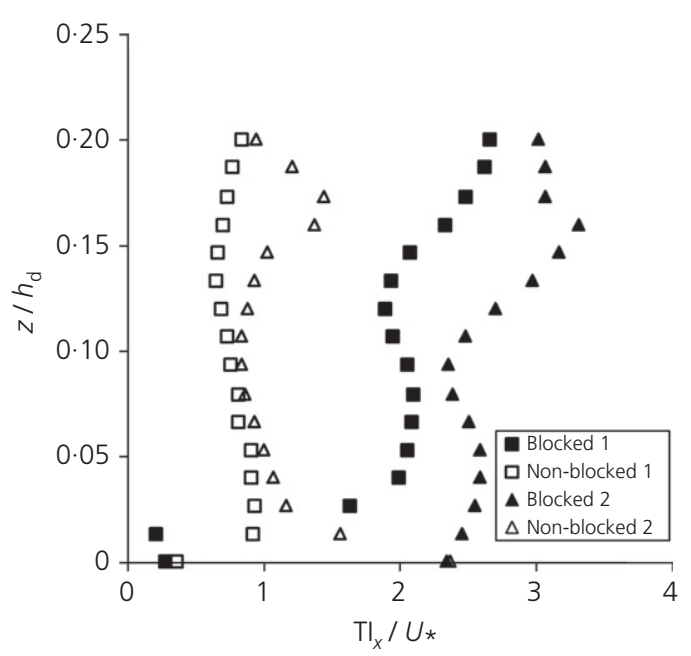

(a)

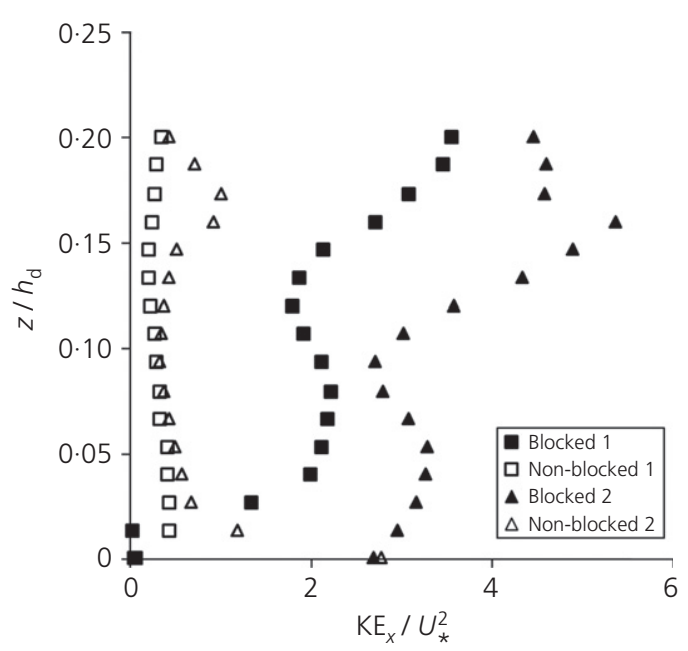

(b)

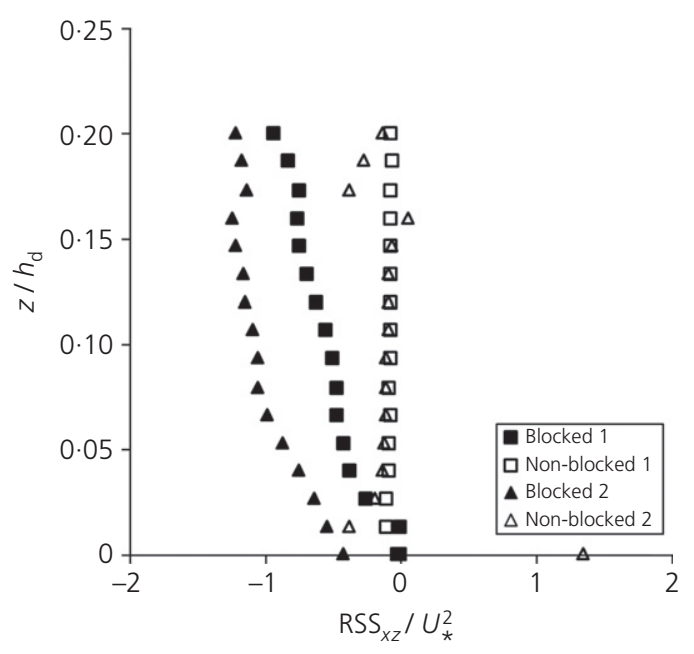

(c)

Figure 5. Variation of non-dimensional flow characteristics in depth at the outlet of the culvert: (a) turbulence intensity $\left(\mathrm{TI}_{x}\right)_{\text {; }}$ (b) kinetic energy $\left(\mathrm{KE}_{x}\right)$; (c) Reynolds shear stress (RSS $\mathrm{C}_{x z}$ )

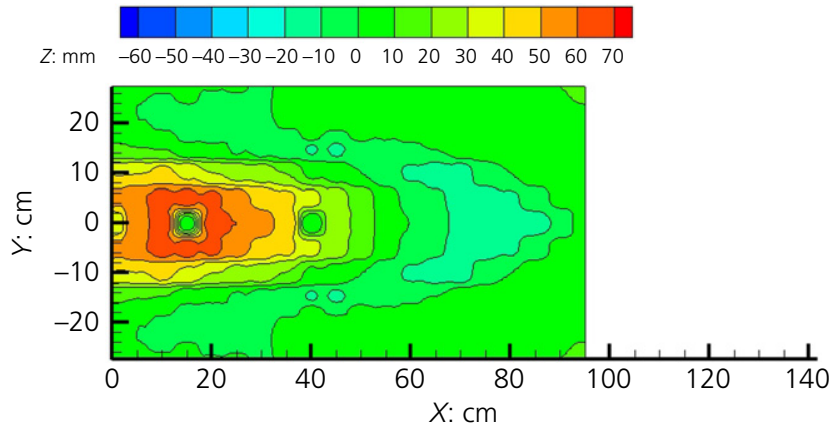

(a)

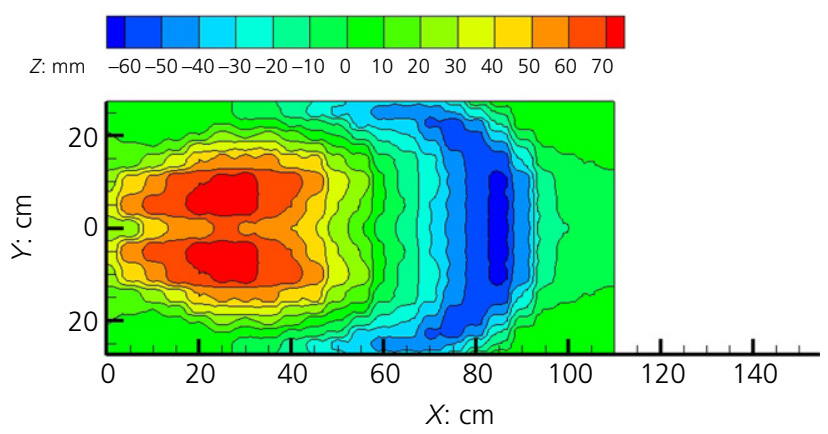

(b)

Figure 6. Contour results: (a) non-blocked; (b) partially blocked conditions (Sorourian et al., 2012)

\subsection{Scouring hole geometry}

\subsubsection{Equilibrium condition}

For each test, the sediment was set initially to the same level as the outlet of the culvert. Each individual test was run until no significant change in the bed profile was observed. Test durations were for $72 \mathrm{~h}$.

\subsubsection{Scour hole extent}

Figure 6 shows the development of the scour hole for two experimental tests, S1B01, which was a non-blocked condition (Figure 6(a)), and S1B401, which was a partially blocked condition (Figure 6(b)). Contour plots were used to determine the scouring depth, length and width. The contour plots locate the scour hole in a sand basin and show the mound location in each test. Positive depths indicate the erosion and negative depths show where aggradation occurs. A comparison between these two conditions shows that the scour hole for a partially blocked culvert generally is larger than for a non-blocked culvert. Figure 6(a) illustrates that the scour width for the nonblocked condition was $400 \mathrm{~mm}$, whereas the scour width for the blocked condition, as shown in Figure 6(b), was $500 \mathrm{~mm}$, which is a $25 \%$ increase in scour width.

\subsubsection{Scouring area}

In the present study, the scoured area $\left(A_{\mathrm{s}}\right)$ is defined as an area below bed level along the centreline which is eroded by water 


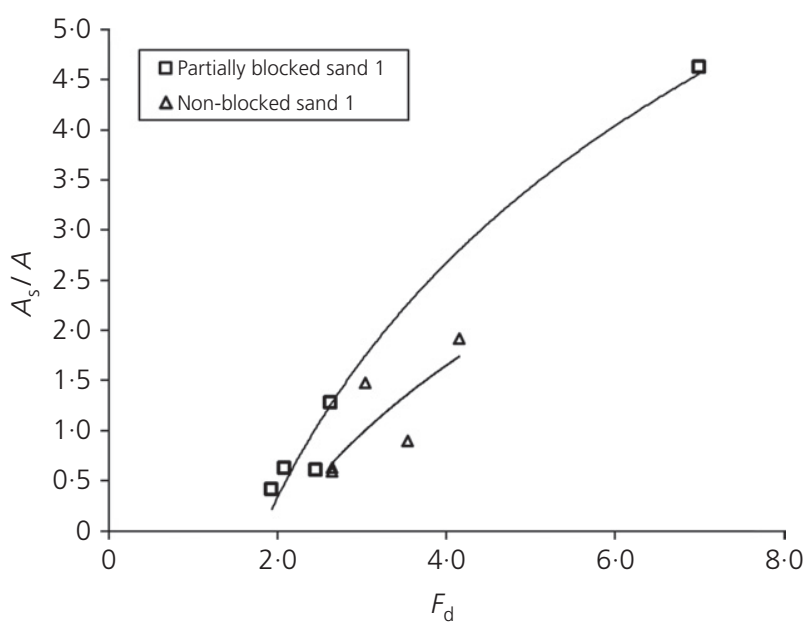

(a)

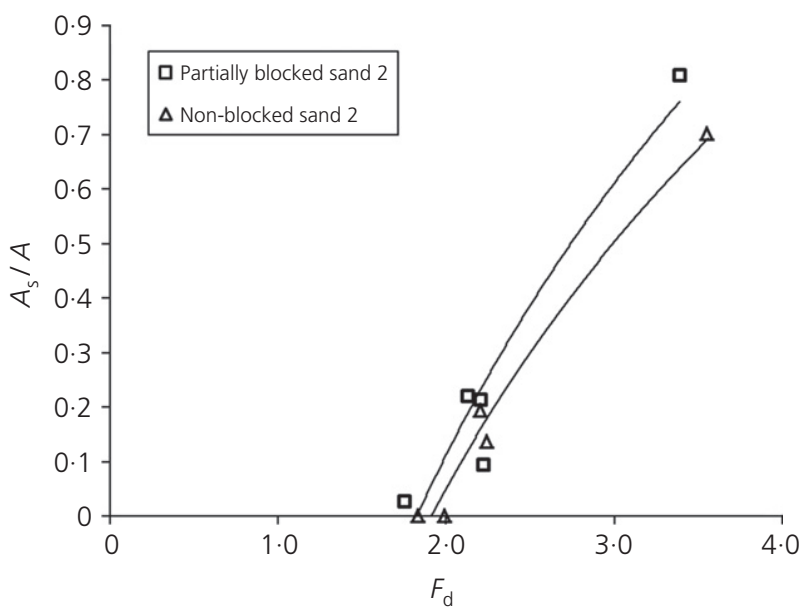

(b)

Figure 7. Scoured area plotted against densimetric Froude number: (a) sediment median size $\left(d_{50}=0.85 \mathrm{~mm}\right)$; (b) sediment median size $\left(d_{50}=2.0 \mathrm{~mm}\right)$

(Figure 2(b)). The scoured area is normalised by the area of the culvert outlet $(A)$. Figure 7 shows the normalised scoured area for partially blocked and non-blocked culverts for two sediment types. As can be seen, the scoured area increases with densimetric Froude number. Although the general trend of the scoured area $\left(A_{\mathrm{S}}\right)$ for the partially blocked and non-blocked conditions is the same, for each densimetric Froude number the value of $A_{\mathrm{s}}$ in the partially blocked condition is greater than in the non-blocked condition. It is also demonstrated that the increase in the scoured area between partially blocked and non-blocked conditions increases with the rise of densimetric Froude number (Figure 7).

\subsubsection{Scouring profile along centreline}

Centreline bed profiles were measured after equilibrium conditions were obtained. Figure 8 depicts the normalised

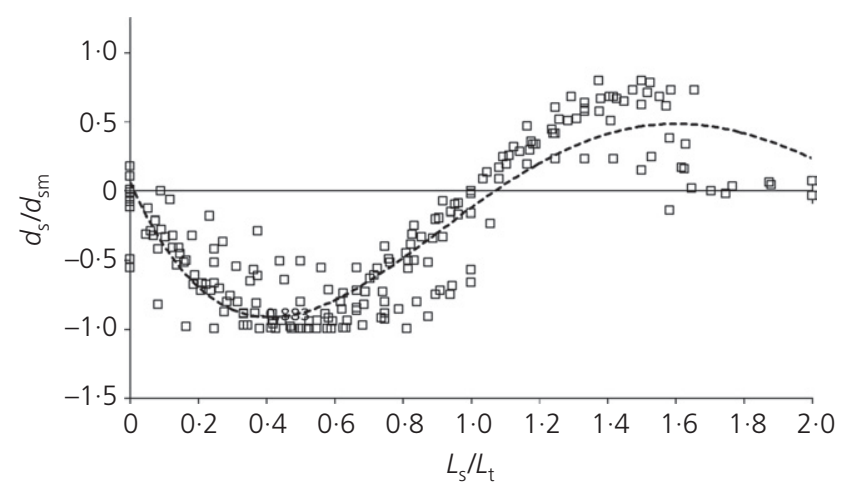

(a)

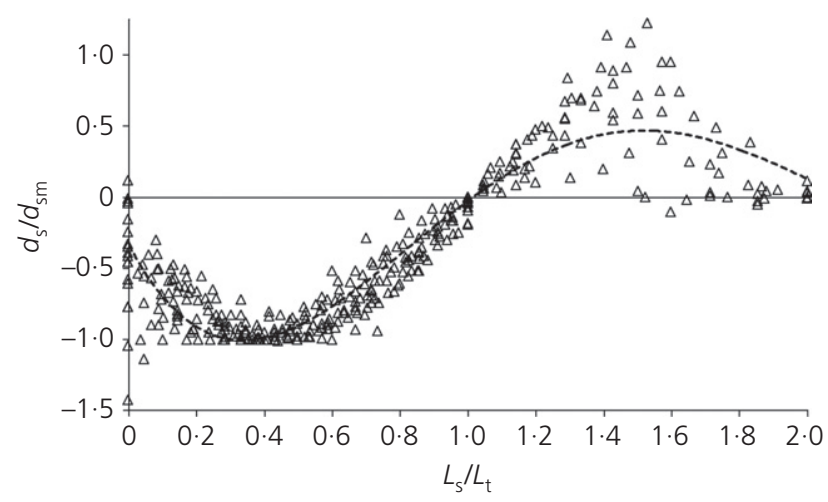

(b)

Figure 8. Normalised scouring profile along centreline: (a) non-blocked condition; (b) partially blocked condition

bed profile scouring for partially blocked and non-blocked conditions. The bed profiles were normalised by the maximum scouring depth $\left(d_{\mathrm{sm}}\right)$. In the horizontal direction, a non-dimensional length was achieved by normalising the distance of any point from the culvert $\left(x_{\mathrm{s}}\right)$ to the total length of the scour $\left(L_{\mathrm{t}}\right)$.

Both profiles were estimated by a fourth-order polynomial. For a non-blocked condition (Figure 5(a)), the estimated bed profile is given by

6

$$
\begin{aligned}
\left(\frac{d_{\mathrm{s}}}{d_{\mathrm{sm}}}\right)= & 0.82\left(\frac{x_{\mathrm{s}}}{L_{\mathrm{t}}}\right)^{4}-4.97\left(\frac{x_{\mathrm{s}}}{L_{\mathrm{t}}}\right)^{3}+9.43\left(\frac{x_{\mathrm{s}}}{L_{\mathrm{t}}}\right)^{2} \\
& -5.46\left(\frac{x_{\mathrm{s}}}{L_{\mathrm{t}}}\right)-0.06
\end{aligned}
$$

In this equation, $d_{\mathrm{s}}$ is the scouring depth at any location along the $X$ direction; $d_{\mathrm{sm}}$ is the maximum scouring depth; $x_{\mathrm{s}}$ is the distance of any point from the culvert outlet along the $X$ direction; and $L_{\mathrm{t}}$ is the total length of scouring hole. The location of maximum scouring depth can be reached by taking the derivative of the scouring profile and making it equal to zero. From Equation 6 the maximum scouring depth occurs at a location equal to $0 \cdot 41$ of the total scouring length $\left(L_{\mathrm{t}}\right)$. Also, at the outlet of the culvert, the scouring depth for the 
non-blocked condition is equal to 0.05 of maximum scouring depth.

For the blocked condition (Figure 5(b)), the estimated bed profile is given by

7.

$$
\begin{aligned}
\left(\frac{d_{\mathrm{s}}}{d_{\mathrm{sm}}}\right)= & 0.93\left(\frac{x_{\mathrm{s}}}{L_{\mathrm{t}}}\right)^{4}-5.24\left(\frac{x_{\mathrm{s}}}{L_{\mathrm{t}}}\right)^{3}+9.14\left(\frac{x_{\mathrm{s}}}{L_{\mathrm{t}}}\right)^{2} \\
& -4.51\left(\frac{x_{\mathrm{s}}}{L_{\mathrm{t}}}\right)-0.33
\end{aligned}
$$

The maximum scouring depth for this condition occurs at 0.33 of the total scouring length, which is $25 \%$ closer to the culvert outlet compared to the non-blocked condition.

Additionally, the scouring depth at the outlet of a partially blocked culvert is equal to 0.33 of maximum scouring depth. This is $5 \cdot 5$ times greater than the depth of scouring at the outlet of the culvert in a non-blocked condition.

\subsubsection{Transverse scouring profile}

Figure 9 shows the non-dimensional transverse bed profiles for partially blocked and non-blocked conditions. The transverse profiles were measured in the $Y$ direction at the maximum scour point for each test. The horizontal axis in Figure 9 is the normalised scour width $\left(y_{\mathrm{s}} / W\right)$ where the culvert width $(W)$ was used as the normalising transverse length. Similarly to the longitudinal scour profile, a polynomial regression equation was developed for non-blocked and partially blocked conditions. For the non-blocked conditions, the transverse profile is given by

8. $\left(\frac{d_{\mathrm{s}}}{d_{\mathrm{sm}}}\right)=0 \cdot 154\left(\frac{y_{\mathrm{s}}}{W}\right)^{2}-0 \cdot 853$

From Equation 8, the maximum non-dimensional scouring width for the non-blocked condition can be obtained by setting $\left(d_{\mathrm{s}} / d_{\mathrm{sm}}\right)$ equal to zero. In this case, the non-dimensional scouring width for the non-blocked condition is $4 \cdot 7$.

For a partially blocked culvert the transverse profile (Figure 9(b)) is given by

9. $\left(\frac{d_{\mathrm{s}}}{d_{\mathrm{sm}}}\right)=0.125\left(\frac{y_{\mathrm{s}}}{W}\right)^{2}-0.952$

Using a similar logic as for the non-blocked condition, the maximum scouring width for the partially blocked condition would be $5 \cdot 5$, which is $17 \%$ more than the scouring width in the non-blocked condition.

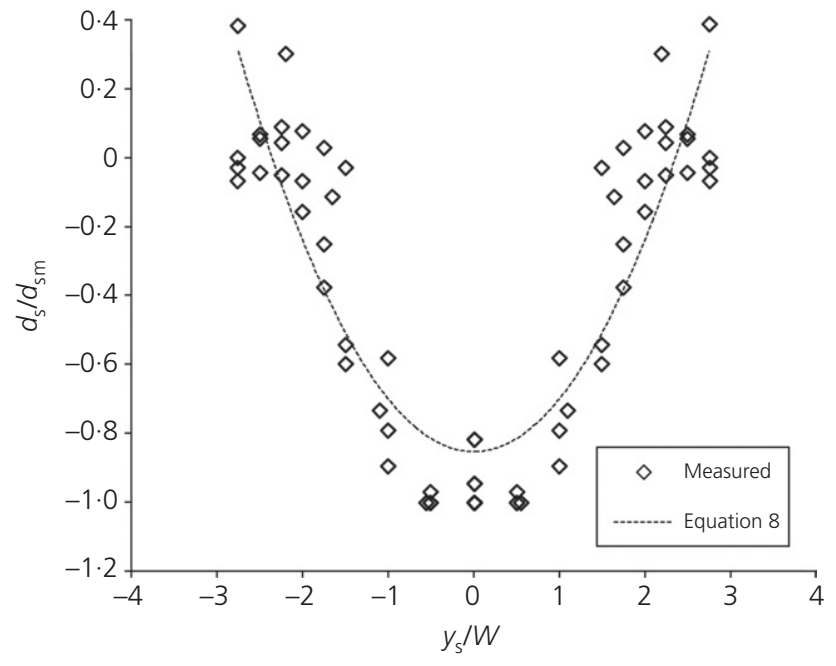

(a)

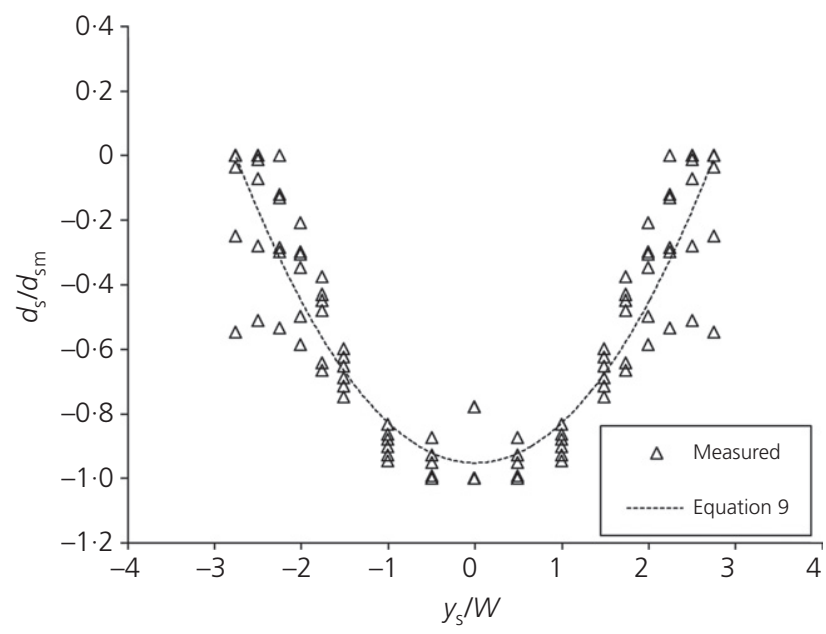

(b)

Figure 9. Non-dimensional transverse scouring profiles for sand 1: (a) non-blocked condition; (b) partially blocked condition

The preceding analysis has shown that blockage has a significant effect on the scouring geometry at the outlet of culverts. When the culvert is partially blocked, the extent of the scouring hole, including its depth, width and length, would be longer than in the non-blocked condition. Therefore, predicting the maximum scouring depth of culverts in the partially blocked condition has significant importance.

\subsection{Scouring depth prediction}

Over past decades several equations have been proposed to estimate the maximum scouring depth at the outlet of culverts in non-blocked conditions. Figure 10 shows a comparison of the maximum scouring depth for a partially blocked condition with some of the recent equations for non-blocked conditions. As shown in this figure, for the same range of $F_{\mathrm{d}}$, the maximum scouring depth for a partially blocked condition is greater than 


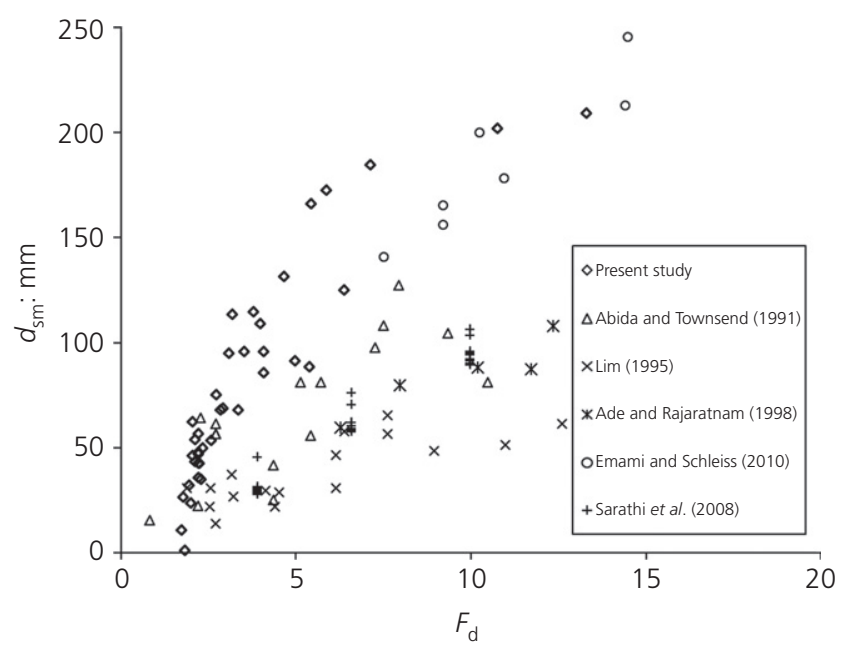

Figure 10. Comparison of maximum scouring depth for present study of the same densimetric Froude number with some of the recent works

that for a non-blocked condition. Therefore, the previously proposed equations for non-blocked conditions are not suitable to estimate the partially blocked conditions accurately.

Based on the results of about 40 experiments, an equation was developed to estimate the maximum scouring depth downstream of a partially blocked culvert; this equation is

10. $\frac{d_{\mathrm{sm}}}{h_{\mathrm{d}}}=0 \cdot 27 F_{\mathrm{d}}+0 \cdot 29 B-0 \cdot 35$

In this equation the maximum scouring depth is a function of the densimetric Froude number $\left(F_{\mathrm{d}}\right)$ and degree of blockage $(B)$. Parameter $B$ is defined by

11. $B=\frac{h_{\mathrm{B}}}{h_{\mathrm{u}}}$

In this equation, $h_{\mathrm{B}}$ is the height of the blockage at the culvert inlet and $h_{\mathrm{u}}$ is the upstream water level. The coefficient of correlation $\left(R^{2}\right)$ for Equation 10 is 0.887 and the standard error of estimate $\left(S_{\mathrm{E}}\right)$ equals $0 \cdot 259$. Figure 11 shows a comparison of the measured maximum scour depth with the scouring depth estimated using the proposed equation. As shown in this figure, a reasonable correlation was achieved.

\section{Comparison with previous scour equations}

Several equations have been proposed to predict the maximum scour depth. Table 2 provides a summary of experimental works conducted by Lim (1995), Ade and Rajaratnam (1998),

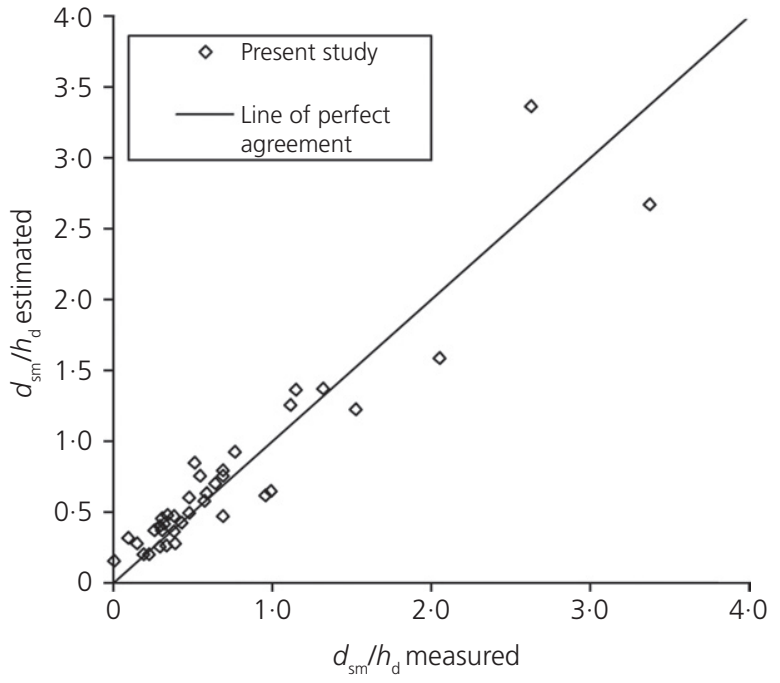

Figure 11. Comparison between measured and estimated $d_{s m} / h_{d}$ for the proposed equation

Sarathi et al. (2008) and Emami and Schleiss (2010), including the condition in which the tests were conducted. As depicted in Table 2, all of these equations considered densimetric Froude number as a main parameter to predict the scouring depth. Some of them, such as Sarathi et al. (2008) and Emami and Schleiss (2010), included the effect of tail water depth in the predictive equation. However, this causes the predictive equation to lack simplicity. All of these experimental tests were conducted in the non-blocked condition and, as a result, the predictive equations are not suitable to estimate scouring downstream from a partially blocked culvert.

Figure 12 shows the data from four experimental studies. A perfect match between predicted and recorded value would occur on a $45^{\circ}$ line. Also shown in this figure are the $\pm 30 \%$ error lines; this value was previously used by Lim (1995) in a similar comparison.

Independent sets of data from the present study, Lim (1995), Ade and Rajaratnam (1998), Sarathi et al. (2008) and Emami and Schleiss (2010) were used to compare with the data calculated using Equation 10 and plotted in Figure 12. As shown in the figure, most of the data are predicted within the $\pm 30 \%$ line. Consideration of the results suggests that the proposed equation in this study has a good agreement with the other data sets. Although the proposed equation includes the blockage ratio $(B)$, it can be used for non-blocked conditions by setting $B$ equal to zero.

\section{Conclusions}

Blockage has not been considered as a key element in studying and estimating the scour at culvert outlets. Hence, the study reported herein focuses on flow structure and sediment 


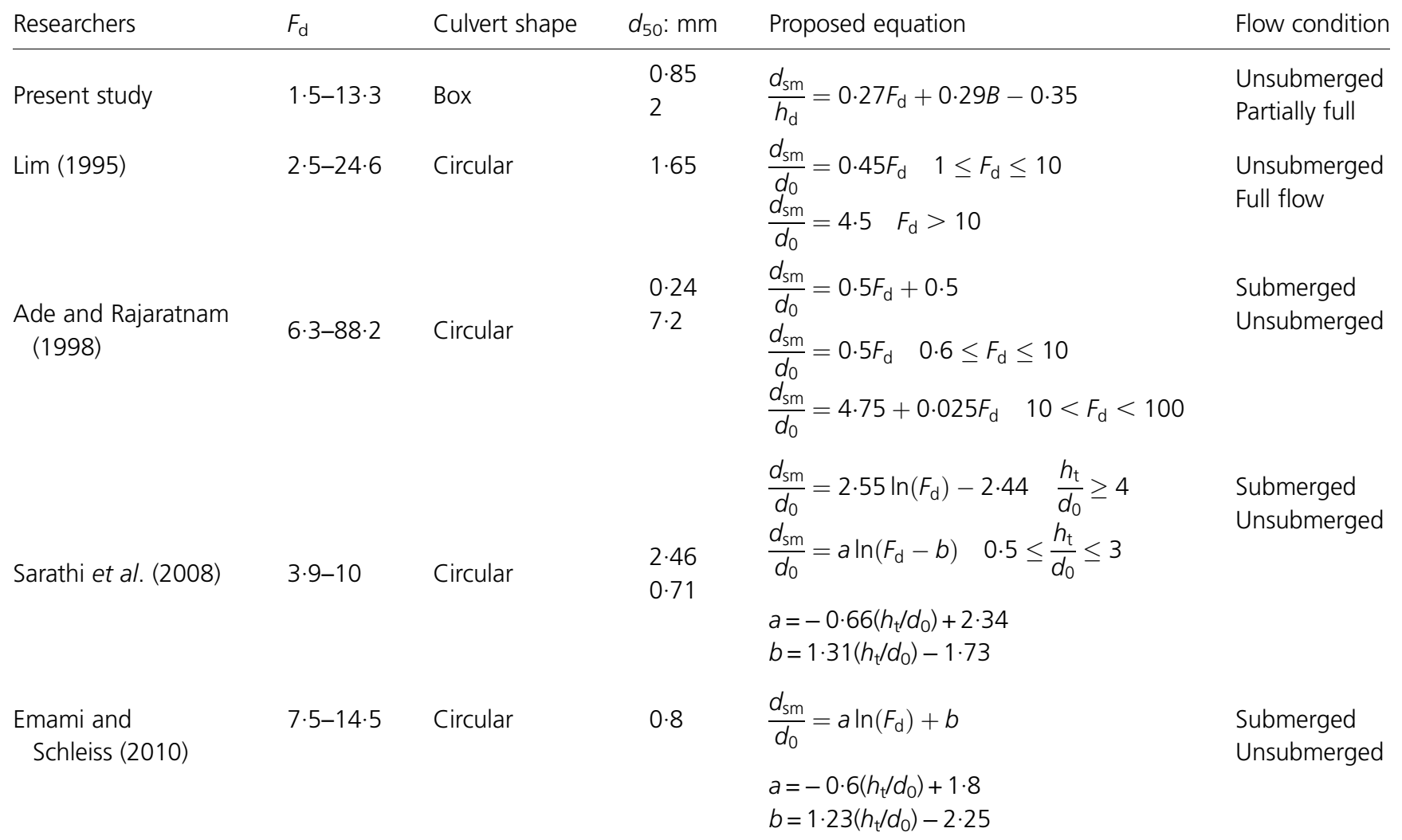

Table 2. Summary of range of experimental tests and proposed equations for recent researchers

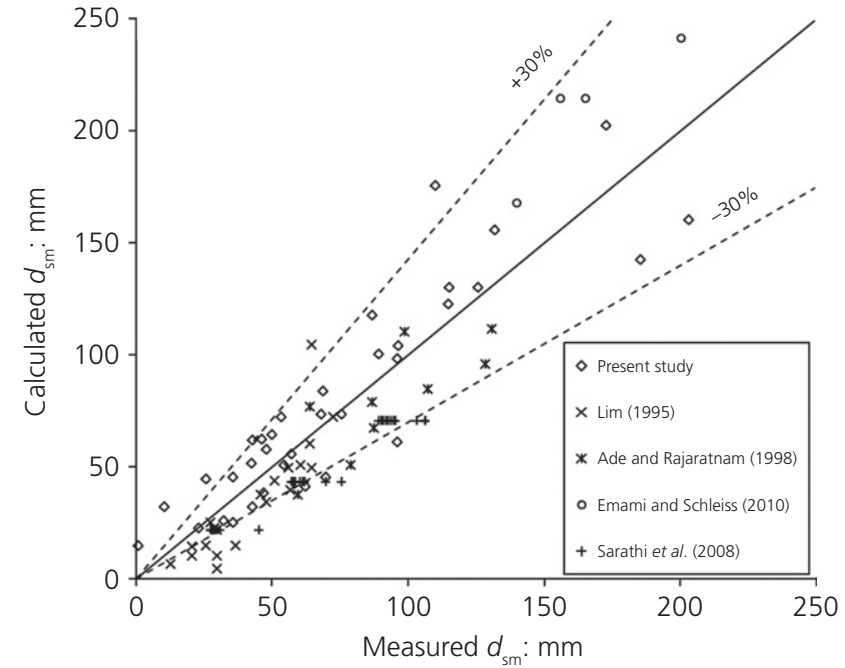

Figure 12. Comparison between values predicted by equations in the present study and measured values for recent experimental equations

transport downstream of a box-culvert for partially blocked and non-blocked conditions. For the experimental tests two different non-cohesive sediment sizes were used.
Results show that blockage has a considerable effect on the flow structure and scouring hole geometry at the outlet of the culvert. The velocity distribution rapidly changes in the culvert barrel for the blocked condition and the average turbulence intensity was found to be three times greater than the non-blocked condition. The scoured area at the blocked culverts was $20-60 \%$ more than non-blocked conditions and scouring width and length increased up to $17 \%$ in the partially blocked conditions. Two equations were proposed to estimate the scouring profile along the centreline and transverse profile, respectively. Results of the maximum scouring depth for the present study were compared with some recent studies in non-blocked conditions and it was noted that maximum scouring depth in the partially blocked condition was greater than the results obtained in a non-blocked condition. Therefore, previously developed formulas in non-blocked conditions are not suitable to estimate outlet scour at partially blocked culverts.

As a result, an equation was proposed to estimate the maximum scouring depth considering the blockage effect. The proposed equation was used to predict the maximum scouring depth in the non-blocked condition using some data from recent studies and could predict the results reasonably accurately. 


\section{REFERENCES}

Abida H and Townsend R (1991) Local scour downstream of box culvert outlets. Journal of Irrigation and Drainage Engineering 117(3): 425.

Abt SR, Kloberdanz RL and Mendoza C (1984) Unified culvert scour determination. Journal of Hydraulic Engineering 110(10): 1475-1479.

Abt SR, Ruff JF and Doehring FK (1986) Culvert slope effects on outlet scour. Journal of Hydraulic Engineering 111(10): 1363-1367.

Abt SR, Ruff J, Doehring F and Donnell C (1987) Influence of culvert shape on outlet scour. Journal of Hydraulic Engineering 113(3): 393-400.

Abt SR, Thompson PL and Lewis TM (1996) Enhancement of the culvert outlet scour estimation equations. Transportation Research Record 1523: 178-185.

Ade F and Rajaratnam N (1998) Generalized study of erosion by circular horizontal turbulent jets. Journal of Hydraulic Research 36(4): 613-636.

Aguirre-Pe J, Olivero MIAL and Moncada AT (2003) Particle densimetric Froude number for estimating sediment transport. Journal of Hydraulic Engineering 129(6): $428-437$.

Ali K and Lim S (1986) Local scour caused by submerged wall jets. Proceedings of the Institution of Civil Engineers, Part 2 81(4): 607-645, http://dx.doi.org/10.1680/iicep.1986.464.

Barthelmess AJ and Rigby E (2011) Estimating culvert \& bridge blockages - a simplified procedure. In Proceedings of the 34th World Congress of the International Association for Hydro-Environment Research and Engineering (Valentine EM, Apelt CJ, Ball J, Chanson H, Cox R, Ettema R, Kuczera G, Lambert M, Melville BW and Sargison JE (eds)). A.C.T., Engineers Australia, Barton, Brisbane, Australia, pp. 39-47.

Bohan JP (1970) Erosion and Riprap Requirements at Culvert and Storm-Drain Outlets. Army Engineers Waterways Experiment Station, Vicksburg, MS, USA, Research report H-70-2, DTIC document.

Breusers H and Raudkivi AJ (1991) Scouring. AA Balkema, Rotterdam, The Netherlands.

Day RA, Liriano SL and White WR (2001) Effect of tailwater depth and model scale on scour at culvert outlets. Proceedings of the Insitution of Civil Engineers - Water and Maritime Engineering 148(3): 189-198.

Emami S and Schleiss AJ (2010) Prediction of localized scour hole on natural mobile bed at culvert outlets. In Scour and Erosion (Burns SE, Bhatia SK, Avila CMC and Hunt BE (eds)). American Society of Civil Engineers, Reston, VA, USA, GSP 210, pp. 844-853.

Lim SY (1995) Scour below unsubmerged full-flowing culvert outlets. Proceedings of the Insitution of Civil Engineers Water Maritime and Energy 112(2): 136-149.

Liriano SL, Day RA and White WR (2002) Scour at culvert outlets as influenced by the turbulent flow structure. Journal of Hydraulic Research 40(3): 367-376.
Rajaratnam N and Berry B (1977) Erosion by circular turbulent wall jets. Journal of Hydraulic Research 15(3): 277-289.

Rigby EH and Barthelmess AJ (2011) Culvert blockage mechanisms and their impact on flood behaviour-are all blockages created equal? In Proceedings of the 34th World Congress of the International Association for HydroEnvironment Research and Engineering, Brisbane, Australia (Valentine EM, Apelt CJ, Ball J, Chanson H, Cox R, Ettema R, Kuczera G, Lambert M, Melville BW and Sargison JE (eds)). Engineers Australia, A.C.T., Barton, Australia, pp. 380-387.

Rigby EH, Boyd MJ, Roso S, Silveri P and Davis A (2002) Causes and effects of culvert blockage during large storms. Proceedings of the 9th International Conference on Urban Drainage, Oregon, USA, pp. 1-16.

Sarathi P, Faruque M and Balachandar R (2008) Influence of tailwater depth, sediment size and densimetric Froude number on scour by submerged square wall jets. Journal of Hydraulic Research 46(2): 158-175.

Sorourian S, Keshavarzi A, Samali B and Ball J (2012) Study of blockage effect on scouring pattern downstream of a box culvert. In Proceedings of the 22nd Australian Conference on the Mechanics of Structures and Materials, ACMSM 22, Sydney, Australia (Samali B, Attard MM and Song C (eds)). CRC Press, Balkema, Rotterdam, The Netherlands, pp. 741-744.

Weeks W, Barthelmess A, Rigby E and Witheridge G (2009) Project 11: blockage of hydraulic structures. In Australian Rainfall and Runoff: Revision Projects (Ball J (ed.)). Engineers Australia, Barton, ACT, Australia, P11/S1/007.

\section{HOW CAN YOU CONTRIBUTE?}

To discuss this paper, please email up to 500 words to the editor at journals@ice.org.uk. Your contribution will be forwarded to the author(s) for a reply and, if considered appropriate by the editorial board, it will be published as discussion in a future issue of the journal.

Proceedings journals rely entirely on contributions from the civil engineering profession (and allied disciplines). Information about how to submit your paper online is available at www.icevirtuallibrary.com/page/authors, where you will also find detailed author guidelines. 